\title{
NONLINEAR DIFFERENTIAL INEQUALITY
}

\author{
N. S. HOANG AND A. G. RAMM
}

Abstract. A nonlinear differential inequality is formulated in the paper. An estimate of the rate of growth/decay of solutions to this inequality is obtained. This inequality is of interest in a study of dynamical systems and nonlinear evolution equations in Banach spaces. It is applied to a study of global existence of solutions to nonlinear partial differential equations.

Mathematics subject classification (2010): 26D10, 37L05, 47J35, 65J15.

Keywords and phrases: Nonlinear inequality; Dynamical Systems Method (DSM); stability.

\section{REFERENCES}

[1] Yu. L. Daleckit, M. G. Krein, Stability of solutions of differential equations in Banach spaces, Amer. Math. Soc., Providence, RI, 1974.

[2] B. P. Demidovich, Lectures on stability theory, Nauka, Moscow, 1967 (in Russian)

[3] P. Hartman, Ordinary differential equations, J. Wiley, New York, 1964.

[4] N. S. HoAng, A. G. Ramm, Dynamical Systems Gradient Method for solving nonlinear operator equations with monotone operators, Acta Appl. Math., 106, (2009) , 473-499.

[5] N.S. HoANG AND A. G. RAMm, A nonlinear inequality, J. Math. Inequal., 2, 4, (2008), 459-464.

[6] N.S. HoAng AND A. G. RAmm, A nonlinear inequality and applications, Nonlinear Analysis: Theory, Methods \& Applications, 71, (2009), 2744-2752.

[7] M. A. KRASNOSEL'SKII, The operator of translation along the trajectories of differential equations. Translations of Mathematical Monographs, Vol. 19, Providence, R.I. 1968.

[8] S. G. Krein, Linear differential equations in Banach spaces, Amer. Math. Soc., Providence, RI, 1971.

[9] V. Lakshmikantham, S. Leela, Differential and integral inequalities; theory and applications, Academic Press, New York, 1969.

[10] A. PAZY, Semigroups of linear operators and applications to partial differential equations, SpringerVerlag, New York, 1983.

[11] A. G. RAmm, Dynamical systems method for solving operator equations, Elsevier, Amsterdam, 2007.

[12] A. G. RAMm, Asymptotic stability of solutions to abstract differential equations, Journ of Abstract Diff. Equations, (JADEA), 1, 1, (2010), 27-34.

[13] J. SCHRÖDER, Operator inequalities, Acad. Press, New York, 1980.

[14] J. SZARSKI, Differential inequalities, PWN, Warszawa, 1967. 